\title{
Using the Ilizarov technique to treat limb shortening after replantation of a severed lower limb: a case report
}

\author{
Qing Jiang', Kai Huang', Yiyang Liu², Genying Chi ${ }^{2}$ \\ ${ }^{1}$ Department of Anesthesiology, ${ }^{2}$ Department of Orthopedics, Tongde Hospital of Zhejiang Province, Hangzhou, China \\ Correspondence to: Genying Chi, BS. Department of Orthopedics, Tongde Hospital of Zhejiang Province, 234 Gucui Road, Hangzhou, China. \\ Email: hzsltd@163.com.
}

\begin{abstract}
The Ilizarov technique for limb lengthening can solve the problem of shortening deformity due to limb replantation after high-energy injury. However, the specific time-points and speed of limb lengthening and the treatment of complications have been thorny issues. In the present case, a 26-yearold male who presented with 12-cm left limb shortening caused by the replantation of the left severed leg, and then treated with the Ilizarov technique to lengthen it simultaneously on the ends of osteotomy and replanted bone. After the limb length restored to normality, tibia bone transport was performed. Considering the unsatisfactory mineralization of the lengthened segment, the external ring fixator was replaced with a splint for temporary fixation, which accompanied with an angular deformity of the lengthened segment. And then a locking plate plus autologous ilium graft was performed to improve the stability and mineralization of the lengthened bone segment. Finally, left lower limb returned to equal length with right one while standing, and the left ankle joint remained in the functional position. In conclusion, this case showed satisfactory follow-up results in terms of limb function and X-ray images. Our study demonstrated that the Ilizarov technique is an effective treatment for shortening deformity after limb replantation.
\end{abstract}

Keywords: Limb lengthening; Ilizarov; case report

Submitted May 26, 2020. Accepted for publication Aug 05, 2020.

doi: $10.21037 /$ atm-20-5316

View this article at: http://dx.doi.org/10.21037/atm-20-5316

\section{Introduction}

The severing of a lower limb due to high-energy injury is often accompanied by bone and soft-tissue defects $(1,2)$. Managements of severing of lower limbs mainly includes replantation and amputation, which are depended on specific indications and contraindications (3). Although the success rate of limb replantation is high, postoperative limb shortening often occurs to varying degrees (4). Recent studies revealed that the Ilizarov technique could overcome this issue $(5,6)$. The Ilizarov apparatus is an external fixation used to lengthen or reshape limb bones with complex and/ or open bone fractures and in cases of infected non-unions. We here used the law of tension-stress advocated by Ilizarov to stretch bone and extend soft tissue simultaneously, and eventually restore a $12-\mathrm{cm}$ lower limb shortening after replantation. Considering the healing process of soft tissues $(7,8)$, limb lengthening, here, was different from pure bone transport. Liu et al. shared some cases by using Ilizarov technique to treat limb shortening after replantation. But complications of limb pain and delayed union were observed during the lengthening process in this case. These were resolved by effective countermeasures, eventually achieving satisfactory results in this patient. We presented the following case in accordance with the CARE reporting checklist (available at http://dx.doi.org/10.21037/atm-205316).

\section{Case presentation}

A 26-year-old male patient had his left leg wholly severed at mid-calf in a traffic accident (Figures 1,2 ). He was admitted to our hospital $5 \mathrm{~h}$ later for emergency shortening replantation, wherein the limb was shortened by $12 \mathrm{~cm}$ and replanted with full viability. Nineteen weeks later, a 


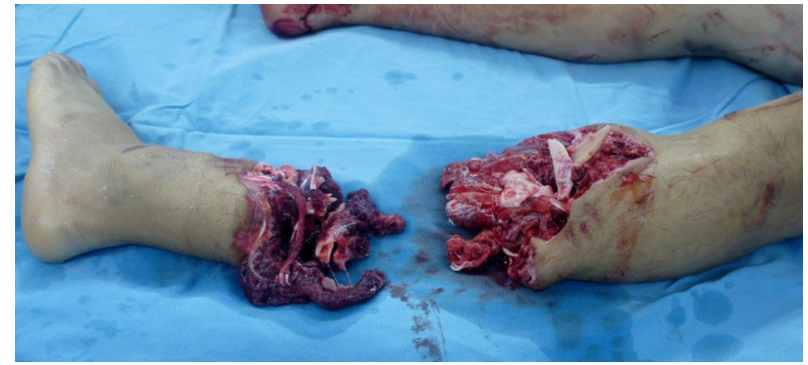

Figure 1 Preoperative image of the severed left leg.

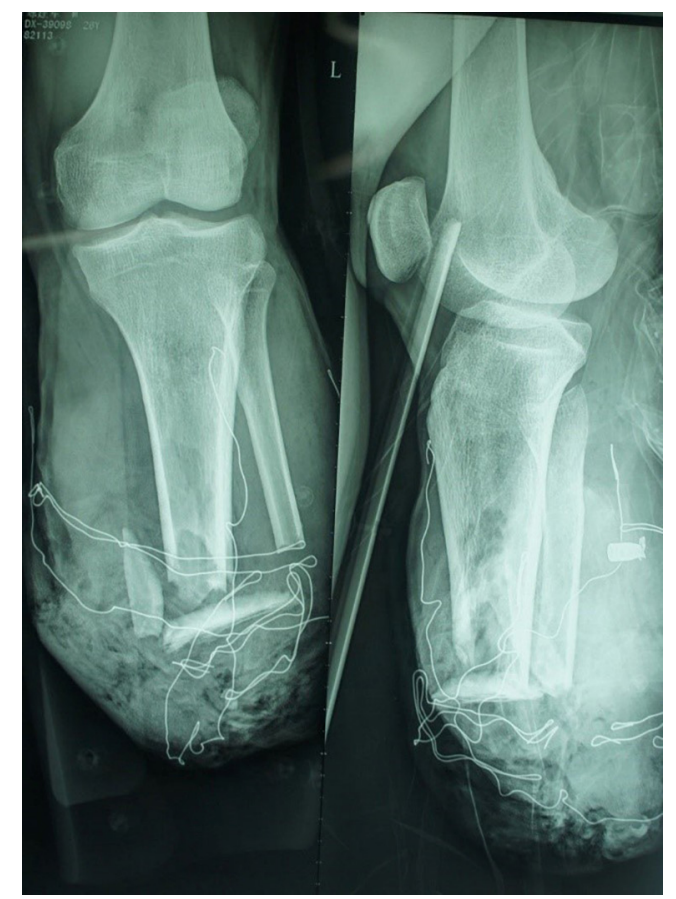

Figure 2 Anteroposterior and lateral X-ray images of the severed left leg.

U-shaped ring was placed on the patient's foot to prevent foot sagging, and osteotomy was performed at the proximal end of the left tibia (Figures 3,4).

One week after surgery, bone lengthening at the rate of $1 \mathrm{~mm} / \mathrm{d}$ was performed simultaneously on the osteotomy end and the replanted bone end. Subsequently, due to local pain, the lengthening rate was decreased to the range of 0.25 to $0.5 \mathrm{~mm} / \mathrm{d}$. Four months later, because the left limb had been restored to normal length, limb lengthening strategy was replaced by tibia bone transport (Figure 5A). However, mineralization of the lengthened segment was found to be unsatisfactory during a follow-up. After 10 months,
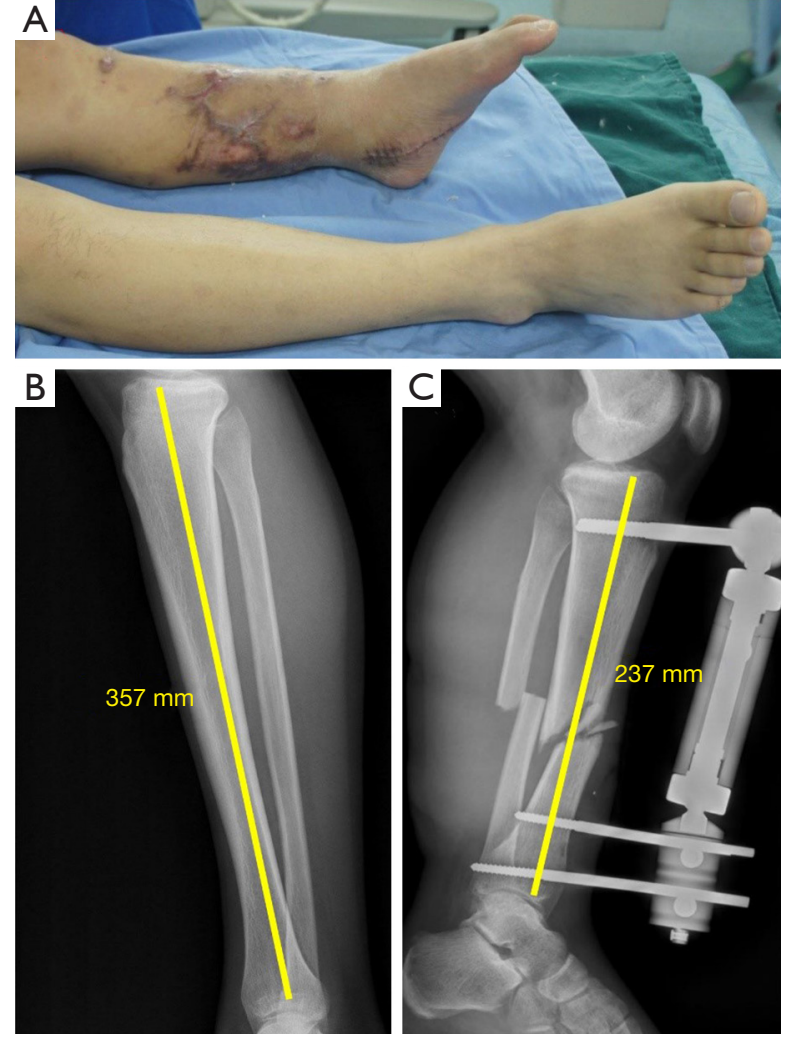

Figure 319 weeks after emergency shortening replantation. (A) The left replanted limb survived with good condition of peripheral circulation of left lower extremity. (B) The right tibia was $357 \mathrm{~mm}$ in length. (C) The left replanted limb length was $237 \mathrm{~mm}$ in length.

the external ring fixator was replaced with a splint for temporary fixation. Unfortunately, due to the loosening of the splint, an angular deformity of the lengthened segment occurred 3 days later (Figure 5B,C). After 12 days, an internal fixation by locking plate plus autologous ilium graft was performed to improve the mineralization of the lengthened bone segment. At 10 weeks postoperatively, both lower limbs showed equal length while standing, and the left ankle joint remained in the functional position. The left knee joint mobility was $0-110^{\circ}$ (Figure $6 A$ ). An X-ray revealed ideal bone healing (Figure $6 B, C$ ), and the sensation was partially recovered in the left plantar.

All procedures performed in studies involving human participants were in accordance with the ethical standards of the institutional and/or national research committee(s) and with the Helsinki Declaration (as revised in 2013). Written informed consent was obtained from the patient. 

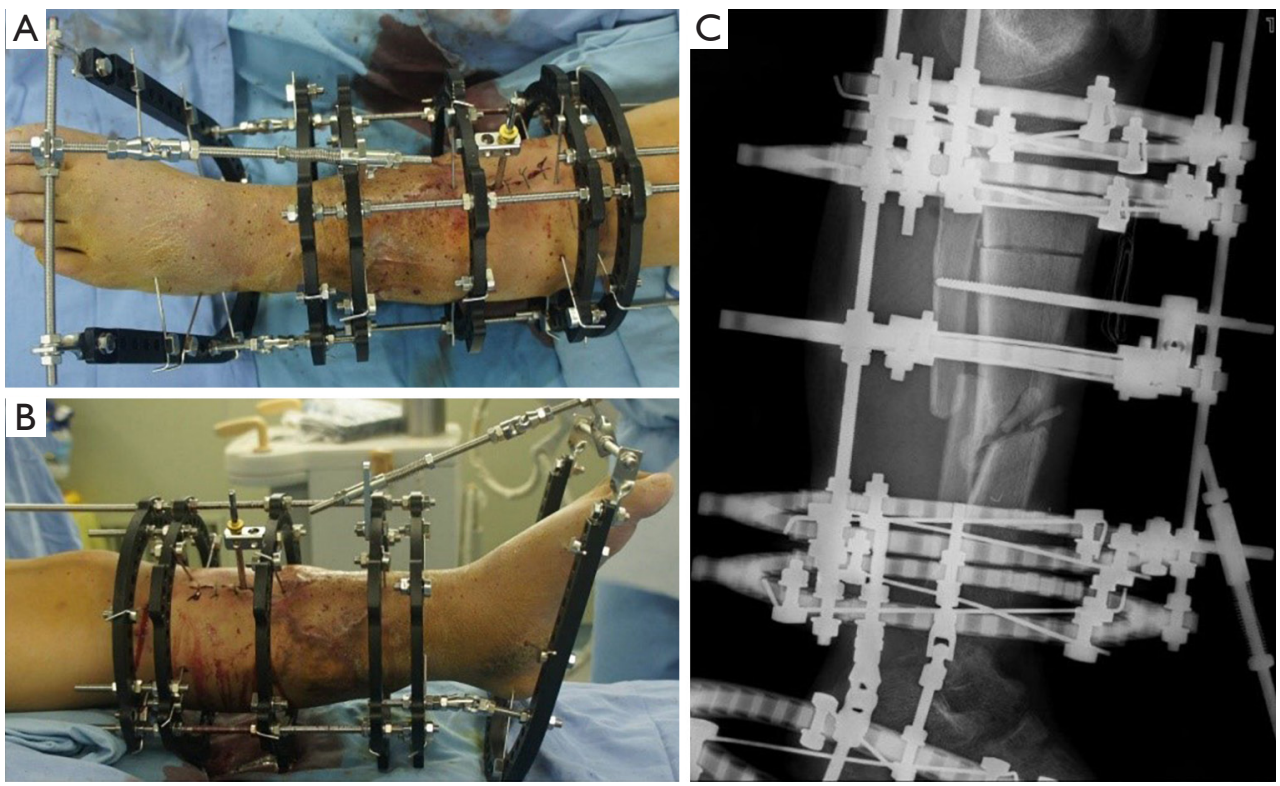

Figure 4 Nineteen weeks after performing the shortening replantation. (A,B) A U-shaped ring was placed on the left foot, and (C) osteotomy was performed at the proximal end of the left tibia.
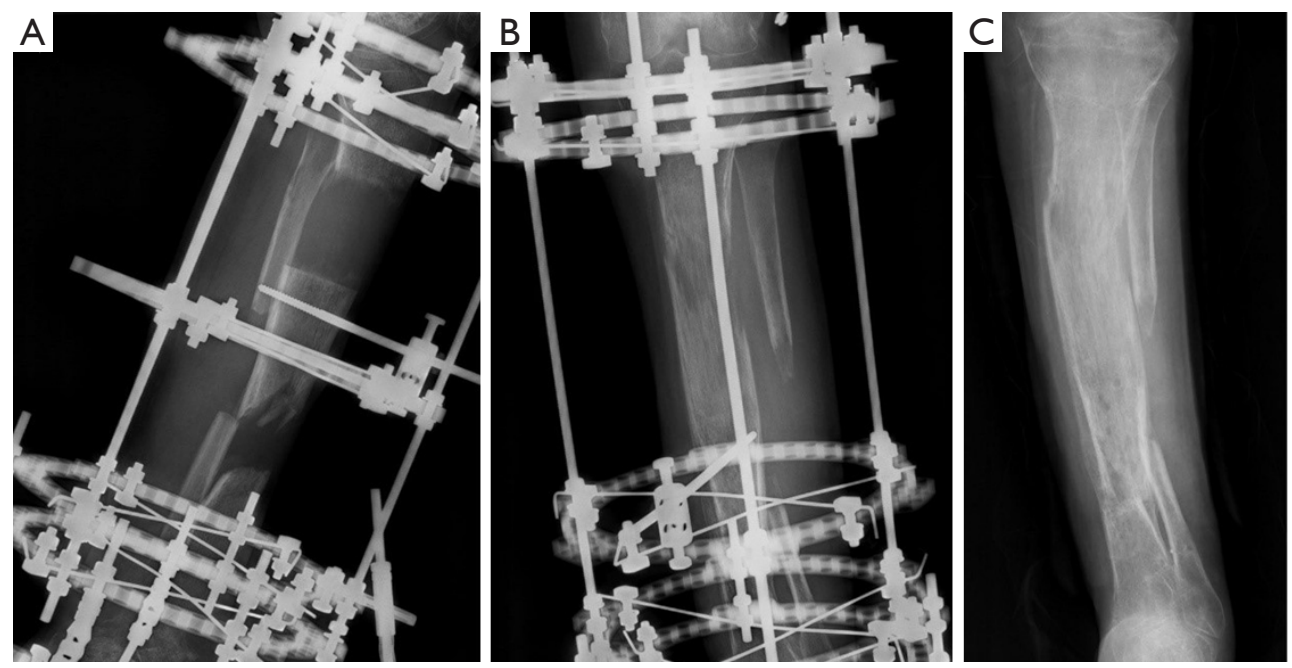

Figure 5 Treated-process of tibia bone transportation. (A) Four months after bone lengthening, tibia bone transport was performed. (B,C) Ten months after bone transport, the external ring fixator was replaced with a splint fixation.

\section{Discussion}

Regarding the choice of lengthening time, the limb lengthening method used for this patient differed from that used in traditional bone transport and the treatment of congenital malformations. Self-repairing and lengthening of skin and soft tissues (nerves, blood vessels, etc.) after anastomosis should be taken into account when lengthening the bone $(9,10)$. The anastomosis of blood vessels, nerves, and tendons take 4 to 8 weeks to heal $(11,12)$. Therefore, limb lengthening should be timed for at least 8 weeks after the successful replantation of the severed limb. In this case report, we initiated a limb lengthening 19 weeks after successful replantation, with consideration of the above factors. 

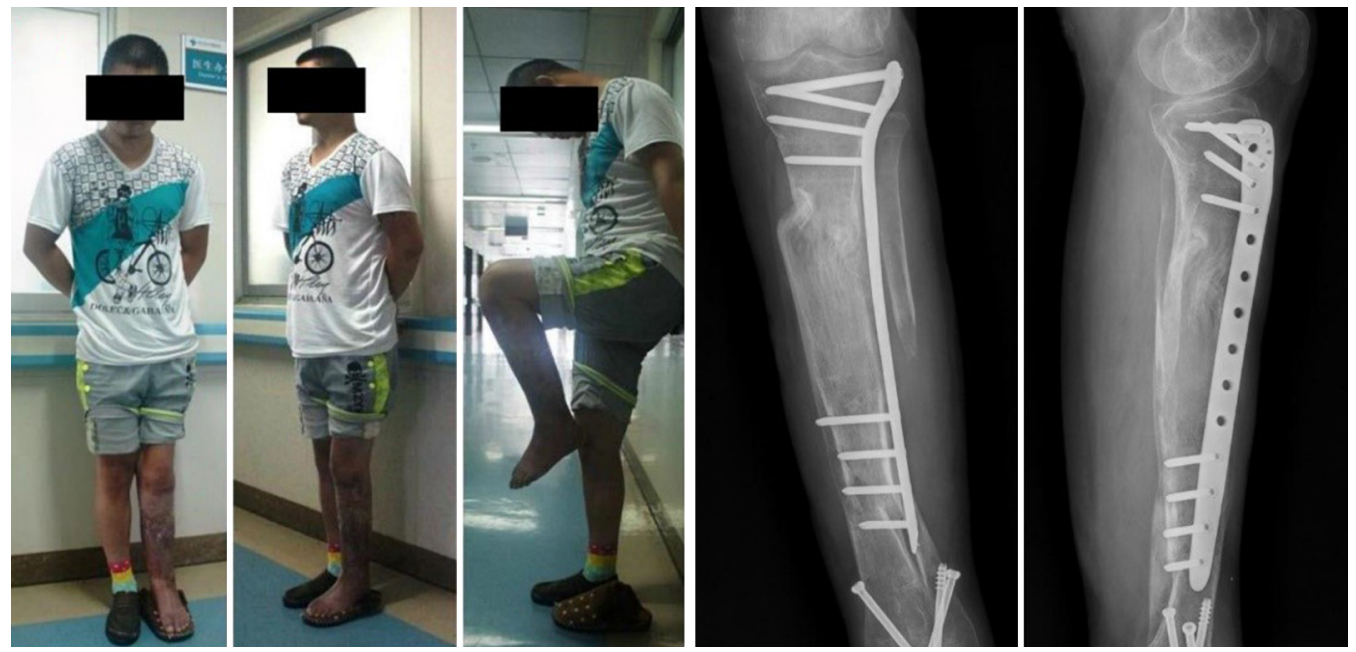

Figure 610 weeks after surgery of internal fixation by locking plate plus autologous ilium graft. (A) The left lower limb recovered satisfactorily concerning limb length, left ankle joint position, and left knee joint mobility. (B) X-ray image of the left tibia at the anteroposterior position. (C) X-ray image of the left tibia at the lateral position.

Lengthening speed is one of the critical factors associated with the success or failure of treatment $(13,14)$. For this patient, we initially adopted the routine protocol for lengthening at $1 \mathrm{~mm} / \mathrm{d}$, which we completed over four sessions. Later, due to limb pain, we gradually slowed down the lengthening rate to a minimum value of $0.25 \mathrm{~mm} / \mathrm{d}$. Relevant research has shown that when lengthening speed $>2 \mathrm{~mm} / \mathrm{d}$, the patient sustains vascular and nerve damage and bone nonunion, whereas when it is $<0.25 \mathrm{~mm} / \mathrm{d}$, the replanted bone will heal in advance, causing bone lengthening to fail (15). In this study, our patient did not experience complications due to the inappropriate lengthening rate. In particular, his recovery of sensation in the sole of his foot eventually confirmed our choices for lengthening timing and rate had been effective.

Poor mineralization in the lengthened segment is a common complication of bone transport (16), and surgical intervention is a treatment measure for this issue. For this patient, we removed the external ring fixator while he was waiting for the operation, and an angular deformity occurred during temporary fixation with the splint. We found that the reduction of angular deformity in the lengthened bone segment was different from that in a fresh fracture. Also, conventional traction and folding reduction were entirely ineffective. Therefore, we recommend that when the lengthened segment does not heal well and requires surgical treatment, surgeons use the more reliable long leg cast for fixation, replacing the external ring fixator before internal fixation. However, the biomechanical mechanism of the ineffectiveness of conventional reduction for the angulated fracture of the extended segment remains unclear.

We have three final points to share. First, compared with the pure bone transport technique, the external ring fixator is applied for a longer-duration limb lengthening, and pin track infection is more likely to occur. Our patient experienced such problems and needed more frequent changes in his wound dressings and oral antibiotics to control the infection. Hence, pin track management throughout treatment is essential. Second, the long-term application of a fixator can cause complications in adjacent joints, especially a high incidence of talipes varus.

For this reason, we placed a U-shaped ring on the foot of the patient's affected leg to prevent drop foot deformity. Finally, in this case, we adopted an extensive treatment cycle, which required high patient compliance and close cooperation between doctor and patient. We gave our weekly patient guidance via online video chat.

Using the Ilizarov technique can effectively treat limb shortening after replantation of a severed limb and expand the indication range of replantation of severed lower limbs. Although a series of complications occurred in the treatment of this patient, the final follow-up results were satisfactory.

\section{Acknowledgments}

Funding: None. 


\section{Footnote}

Reporting Checklist: The authors have completed the CARE reporting checklist. Available at http://dx.doi.org/10.21037/ atm-20-5316

Conflicts of Interest: All authors have completed the ICMJE uniform disclosure form (available at http://dx.doi. org/10.21037/atm-20-5316). The authors have no conflicts of interest to declare.

Ethical Statement: The authors are accountable for all aspects of the work in ensuring that questions related to the accuracy or integrity of any part of the work are appropriately investigated and resolved. All procedures performed in studies involving human participants were in accordance with the ethical standards of the institutional and/or national research committee(s) and with the Helsinki Declaration (as revised in 2013). Written informed consent was obtained from the patient.

Open Access Statement: This is an Open Access article distributed in accordance with the Creative Commons Attribution-NonCommercial-NoDerivs 4.0 International License (CC BY-NC-ND 4.0), which permits the noncommercial replication and distribution of the article with the strict proviso that no changes or edits are made and the original work is properly cited (including links to both the formal publication through the relevant DOI and the license). See: https://creativecommons.org/licenses/by-nc-nd/4.0/.

\section{References}

1. Ebrahimi A, Nejadsarvari N, Ebrahimi A, et al. Early Reconstructions of Complex Lower Extremity Battlefield Soft Tissue Wounds. World J Plast Surg 2017;6:332-42.

2. Xu J, Zhong WR, Cheng L, et al. The Combined Use of a Neurocutaneous Flap and the Ilizarov Technique for Reconstruction of Large Soft Tissue Defects and Bone Loss in the Tibia. Ann Plast Surg 2017;78:543-8.

3. Langer V. Management of major limb injuries. ScientificWorldJournal 2014;2014:640430.

4. Fufa DT, Lin CH, Lin YT, et al. Survival and secondary surgery following lower extremity replantation. J Reconstr Microsurg 2014;30:419-26.

5. Nisanci M, Er E, Yildiz C, et al. Replantation of a crush amputation of distal tibia followed by lengthening with Ilizarov circular external fixator: two-year follow-up.
Microsurgery 2002;22:295-9.

6. Kanchanathepsak T, Gotani H, Hamada Y, et al. The effectiveness of distraction lengthening in traumatic hand amputation with Ilizarov mini fixator. Injury 2020. [Epub ahead of print].

7. Yang J, Zheng C, Wang H, et al. Cross limb vessel transfer for salvage of the extremity with irreparable artery injury. Injury 2019;50 Suppl 5:S111-6.

8. Uhrig BA, Clements IP, Boerckel JD, et al. Characterization of a composite injury model of severe lower limb bone and nerve trauma. J Tissue Eng Regen Med 2014;8:432-41.

9. Zhu X, Wei H, Zhu H. Nerve wrap after end-to-end and tension-free neurorrhaphy attenuates neuropathic pain: A prospective study based on cohorts of digit replantation. Sci Rep 2018;8:620.

10. Taghinia AH. Pediatric Replantation and Revascularization. Hand Clin 2019;35:155-78.

11. Cheng GL, Pan DD, Qu ZY, et al. Replantation of avulsively amputated thumb: a report of 15 cases. Ann Plast Surg 1985;15:474-80.

12. Ono S, Chung KC. Efficiency in Digital and Hand Replantation. Clin Plast Surg 2019;46:359-70.

13. Betz AM, Hierner R, Baumgart R, et al. Primary shortening--secondary lengthening. A new treatment concept for reconstruction of extensive soft tissue and bone injuries after 3rd degree open fracture and amputation of the lower leg. Handchir Mikrochir Plast Chir 1998;30:30-9.

14. Lesley NE, Pirela-Cruz MA. Distraction lengthening of the thumb following replantation. J Reconstr Microsurg 2005;21:161-5.

15. Ilizarov GA. The tension-stress effect on the genesis and growth of tissues. Part I. The influence of stability of fixation and soft-tissue preservation. Clin Orthop Relat Res 1989;(238):249-81.

16. Wagner F, Vach W, Augat P, et al. Daily subcutaneous Teriparatide injection increased bone mineral density of newly formed bone after tibia distraction osteogenesis, a randomized study. Injury 2019;50:1478-82.

(English Language Editor: J. Chapnick)

Cite this article as: Jiang Q, Huang K, Liu Y, Chi G. Using the Ilizarov technique to treat limb shortening after replantation of a severed lower limb: a case report. Ann Transl Med 2020;8(16):1025. doi: 10.21037/atm-20-5316 